DOI 10.17816/transsyst201843s1328-339

\author{
(C) R. Mishra ${ }^{1}$, H. Sharma ${ }^{1}$, H. Mishra ${ }^{2}$ \\ ${ }^{1}$ ECE Department, KIET Group of Institutions \\ ${ }^{2}$ Dr K.N MIET \\ (Ghaziabad, India)
}

\title{
HIGH-SPEED VACUUM AIR VEHICLE
}

Background: There are a number of problems in the prior art, those are topics of research inputs like ranges of the drag force generated by the vehicle, lift force at high vehicle motion velocities for compensation of the vehicle weight, aerodynamic aspects of operation of the vehicle.

Aim: Stream-wise stability of vehicle motion and levitation as well as braking of the vehicles and supersonic speed are not achieved in any mode of transportation. But this present invention relates to high-speed magnetic levitation transportation using compressed air chamber in the transportation vehicle.

Materials and methods: The present invention relates more particularly related to high-speed vehicle levitated in a vacuum tunnel by using electromagnetic levitation, as this vehicle will move from one place to another in a vacuum environment and this vehicle will levitate above track with the help of electromagnets.

Results: The important thing is its motion, which is possible due to reaction force of high pressure air, coming out from compressed air chamber present in vehicle.

Conclusion: It can give us the acceleration as per load requirement and it can achieve supersonic speed in few seconds.

Keywords: Magnetic levitation, Electromagnets, Magnetic track, High-speed vacuum vehicle, Air train, Transportation, Compressed air train.

\section{INTRODUCTION}

Along with the increase of population and expansion in living zones, automobiles and air services cannot afford mass transit anymore. Accordingly, demands for innovative means of public transportation have increased. In order to appropriately serve the public, such a new generation transportation system must meet certain requirements such as speed, reliability, and safety. In addition, it should be convenient, environmentally friendly, low-maintenance, compact, light-weight, unattained, and suited to mass transportation. We human waste our precious life time for travelling from one place to another. So we need a high-speed transport system which will save our time. Yes, we have such kinds of transport systems like airways, which can reach up to one thousand $\mathrm{km} / \mathrm{h}$ and we also have present magnetic levitation technology which cannot reach sonic speed. Here 
with this invention, transportation method will be safe, quick, efficient and, most significantly, high-speed. And it can change the future scenario of transport method. We also have Hyperloop system, but that idea limits the speed of transportation as it consists of the air compressor in front.

\section{DETAILED DESCRIPTION}

Here Fig. 1 shows exemplary representation of mechanism for formation of compressed air and vacuum creation mechanism according to one of the embodiment of the invention. Here we have used vacuum tunnel as shown in Fig. 1 , inside this tunnel vacuum will be created with the help of vacuum pump. This pump will suck air from tunnel. Next, we will compress air with the help of air compressor.

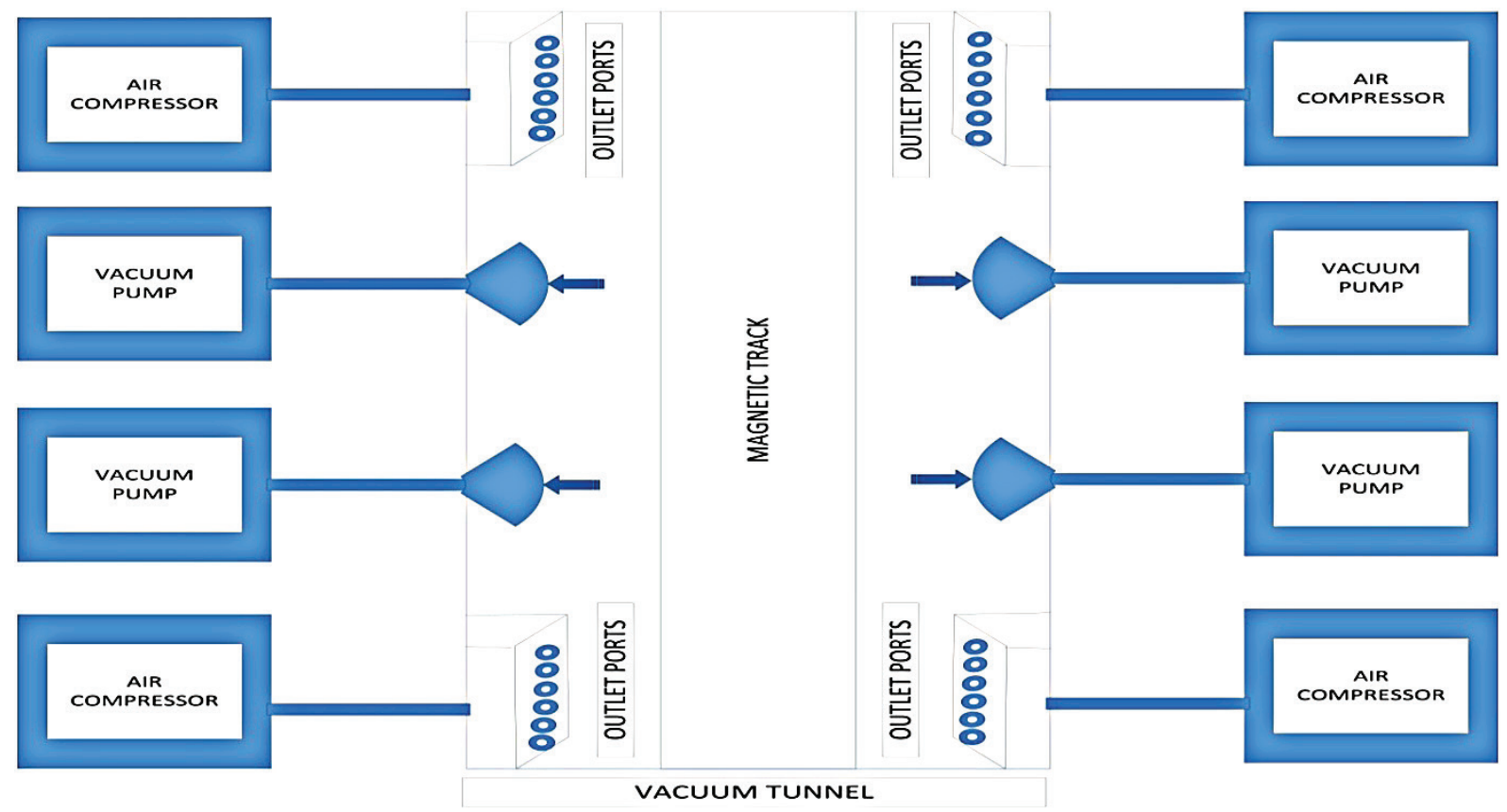

Fig. 1. Setup for vehicle motion on magnetic track

Here outlet ports as shown in Fig. 1 are the part of the air compressor to transfer compressed air to vehicle. And in Fig. 1 magnetic track is the track on which vehicle will levitate and move.

Fig. 2 shows detailed view of vacuum tunnel. Now we come to a vehicle which will levitate above the track and move with a very high speed.

In Fig. 3, we have explained the basic components of a vehicle, such as battery area, crew cabin and passengers' room. And here we have also used high reusable silicon insulation (HRSI) tiles as it does not allow heat transfer in passenger 


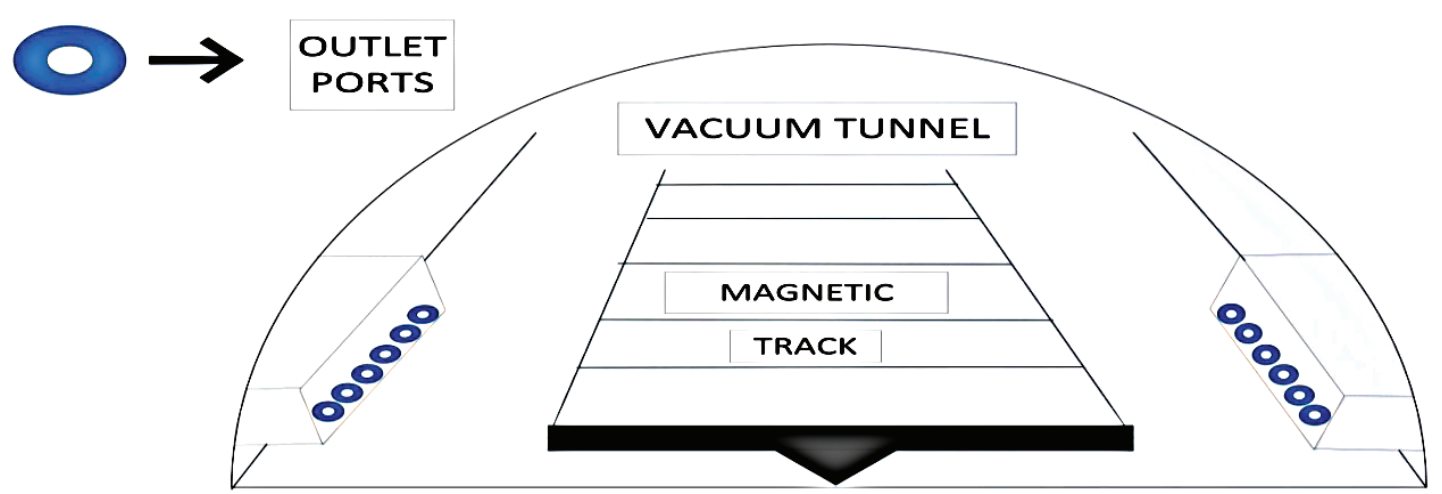

Fig. 2. Inside View of tunnel

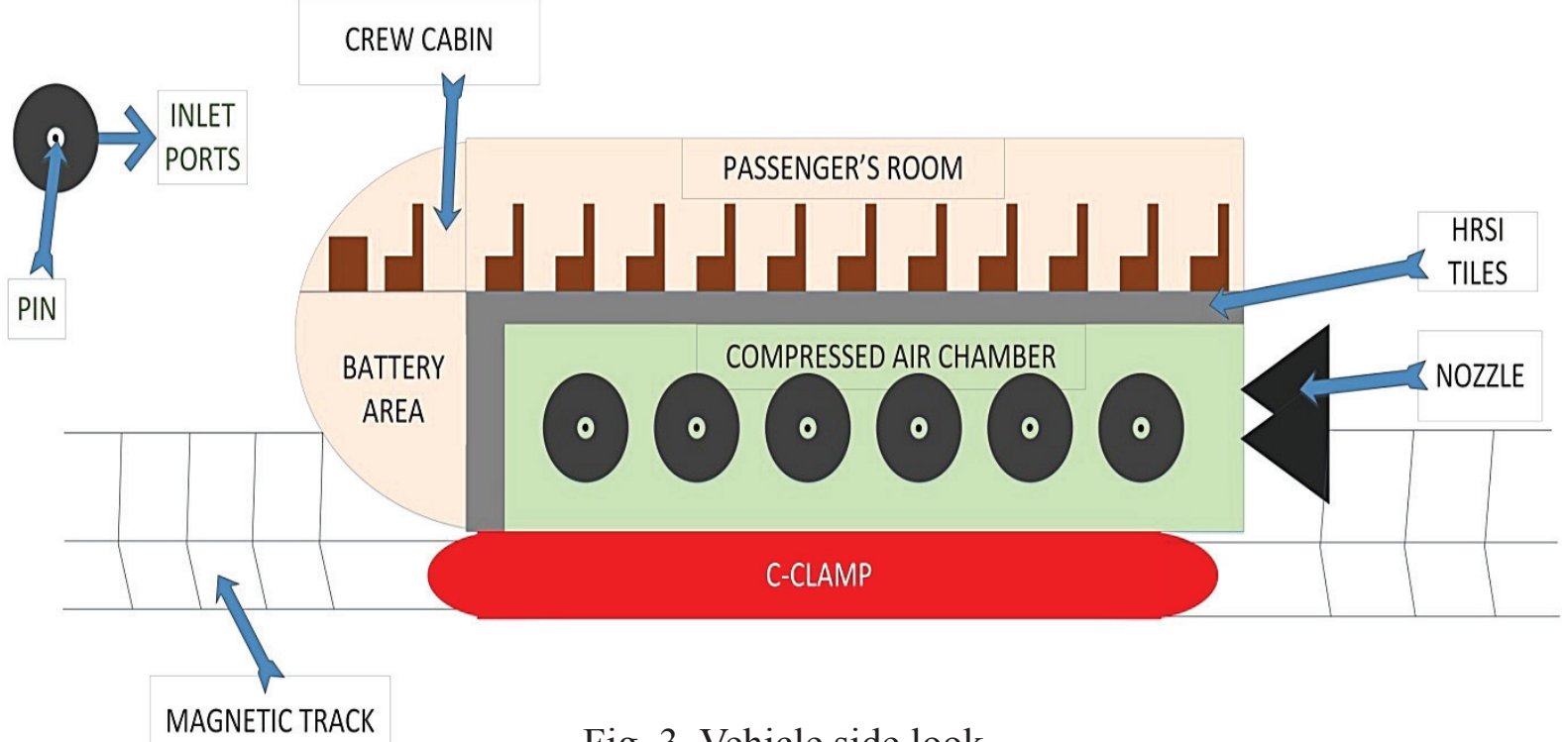

Fig. 3. Vehicle side look

sitting area for safe journey. Here C-clamp is the base of the vehicle, which makes vehicle levitate above the magnetic track. Here compressed air chamber is the closed chamber in which compressed air is filled. Here inlet ports are shown which are used to fill compressed air chamber with compressed air.

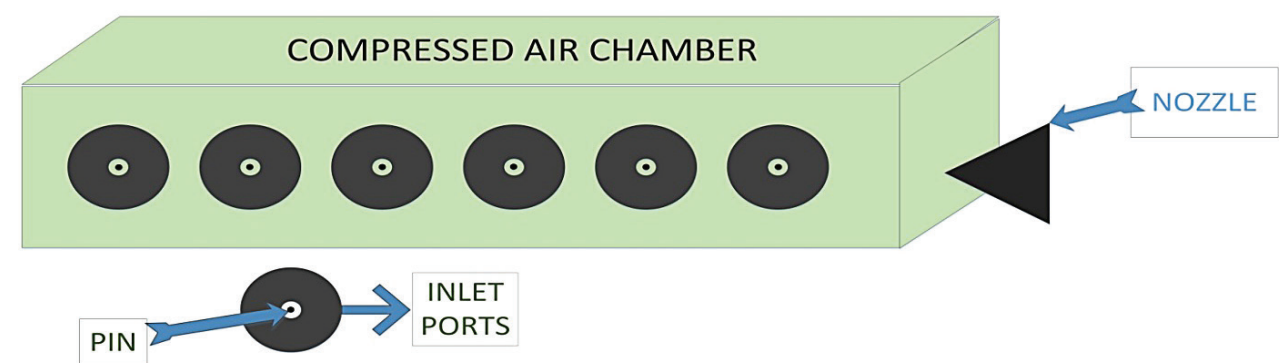

Fig. 4. Look of compressed air chamber 


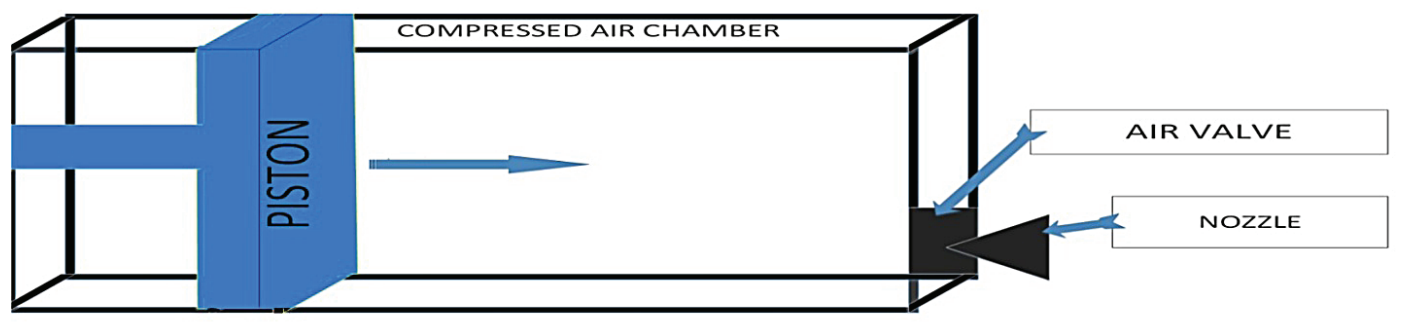

Fig. 4(a). Forward motion of piston

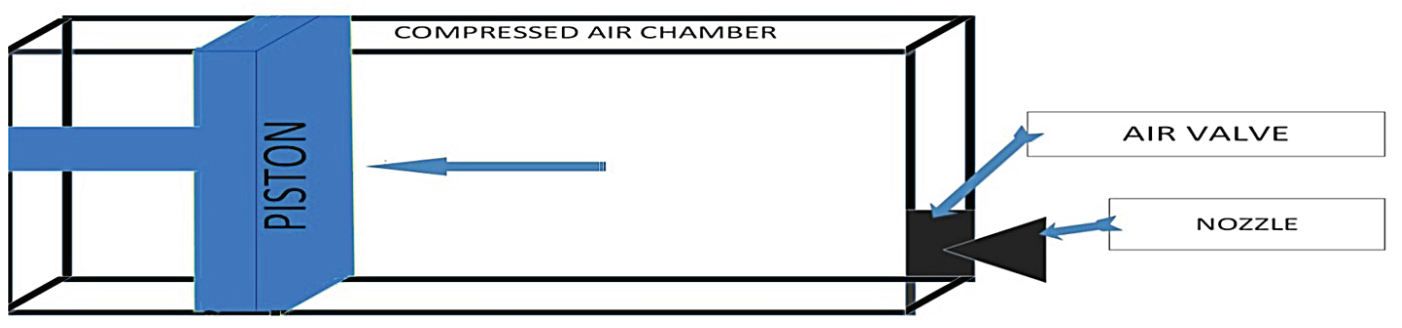

Fig. 4(b). Backward motion of piston

Inside view of compressed air chamber look is shown below in Fig. 4(a) and Fig. 4(b).

Now we will discuss the mechanism of motion of vehicle in forward direction. The outlet ports, as shown in Fig. 1, will transfer compressed air to inlet ports, as shown in Fig. 3, of the vehicle. As the pin, as shown in Fig. 3, gets pushed inside, the entry of compressed air into compressed air chamber starts. This charging of compressed air chamber is done when the vehicle is in rest. See Fig. 4 (2D view of chamber), as compressed air gets inside compressed air chamber, it accumulates until the chamber is full, and then we will release compressed air with the help of valve as shown in Fig. 4(a) and Fig. 4(b), and to enhance effect we have used nozzle which will allow releasing compressed air. As we need a constant pressure throughout exit of the compressed air, we have used a piston. Fig. 4(a) and Fig. 4(b) represent forward and backward motion of the piston. And when compressed air comes out from compressed air chamber via nozzle in control of valve with constant pressure, it provides a huge reaction force which will accelerate our vehicle in opposite direction of the air coming out. Once it gets a required velocity, the valves will be shut off by the command from crew cabin, as shown in Fig. 3, and hence the vehicle will maintain its velocity as it will be in the environment of negligible friction. Compressed air chamber should be made in such a way that it can tolerate high temperature and high pressure.

Here a clear look of nozzle is shown below in Fig. 4(c) and a proper explanation of all the parameters shown in Fig. 4(c) is given as well. 


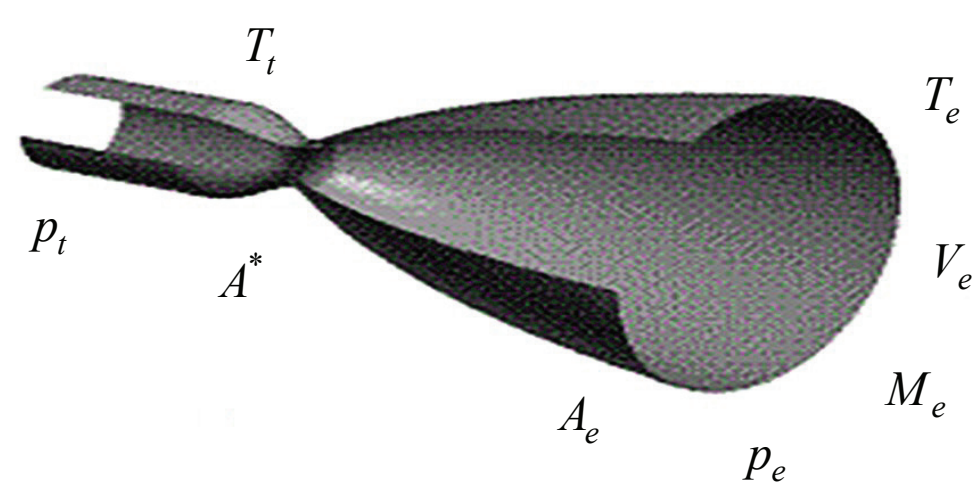

Fig. 4(c). Close view of nozzle

Parameters are explained below as follows:

$T_{t}$ - Total temperature of compressed gas inside compressed air chamber;

$T_{e}$ - Temperature of gas on its way out from nozzle;

$A^{*}$ - Area of cross-section of choked flow region;

$A_{e}$ - Area of cross-section of exit;

$p_{t}$ - Total pressure of compressed gas inside compressed air chamber;

$p_{e}-$ Pressure of gas on its way out from nozzle;

$p_{o}$ - Free stream pressure;

$M_{e}-$ Exit Mach number;

$V_{e}-$ Exit velocity.

Fig. 5 shows an exemplary representation of magnetic levitation and braking system according to the present invention. In Fig. 5, the C-clamp has two L-shaped electromagnets named as C-clamp levitation electromagnets, attached to its base side. And the other L-shaped electromagnet, named track levitation electromagnet, attached to the upper side of the magnetic track. The four track

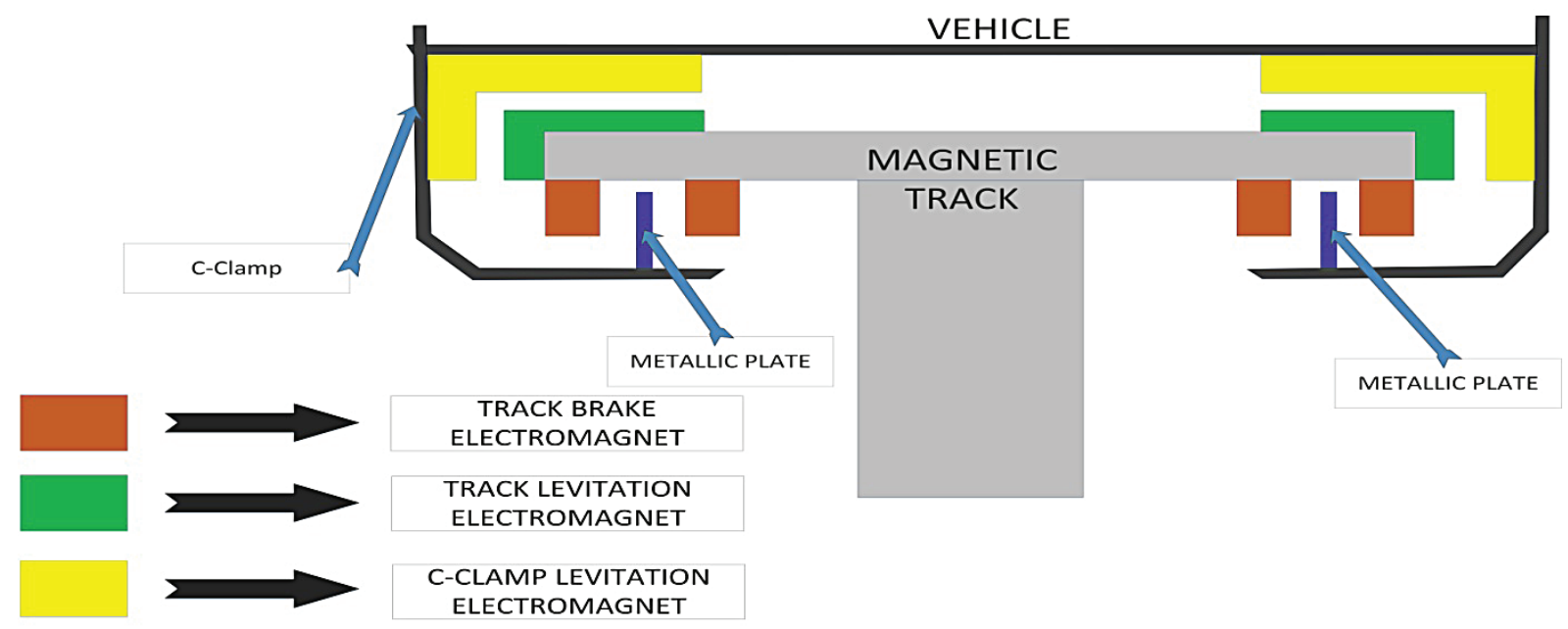

Fig. 5. C-Clamp Analysis 
brake electromagnets are placed at the lower side of the magnetic track. The C-clamp has a metal sheet. The metal sheet is attached to the C-clamp in such a manner that it is placed between at least two track brake electromagnets at the lower side of the magnetic track. This metal sheet is covered with a diamagnetic cover. This cover can be covered and uncovered by control of the vehicle by its control system in crew cabin, as shown in Fig. 3, during braking and levitation of vehicle.

These C-clamp levitation electromagnets of C-clamp and track brake electromagnets of the magnetic track both generate similar poles and develop repulsive force during the normal position of the vehicle. The repulsive force is developed in such a manner that the vehicle loses its contact with the magnetic track and it starts levitating above the magnetic track. If the weight of the vehicle changes then intensity of these electromagnets also changes accordingly automatically.

As Fig. 5 shows, during braking of the vehicle, the four track brake electromagnets of the magnetic track and metal sheets attached to C-clamp come in action. The metal sheets are kept in a diamagnetic envelope until braking is not required. When the vehicle transportation control system, present in crew cabin, as shown in Fig. 3, provides signal to retard motion of the vehicle, then the vehicle transportation control system creates north-south poles in each pair of electromagnets. It is done in such a way that metal sheet lies in between north and south poles of two track brake electromagnets of the magnetic track. As metal sheets are attached to the vehicle body, hence it cuts the magnetic field created by track brake electromagnets of the magnetic track. During this activity, the flux is changed in metal sheets which create eddy currents as described by Faraday's law of induction. By Lenz's law, the circulating currents in the metal sheet create their own magnetic field in the sheet. Thus metal sheet will experience a drag force from the track brake electromagnets of the magnetic track. So it opposes its motion. The kinetic energy of the moving vehicle is dissipated as heat is generated by the current flowing through the electrical resistance of the metal sheet. By the reason of this activity, the metal sheet should bear a high temperature.

The whole magnetic track is divided into segments, and when the vehicle comes near segment electromagnets get active accordingly. Now as our vehicle will face negligible air friction and negligible friction from track, so it is highly efficient. Here in this vehicle we will coat its body with diamagnetic substance so that magnetic field does not affect inside the vehicle.

Fig. 6 is responsible for reversing the direction of vehicle clockwise or counterclockwise with rotating disk. 


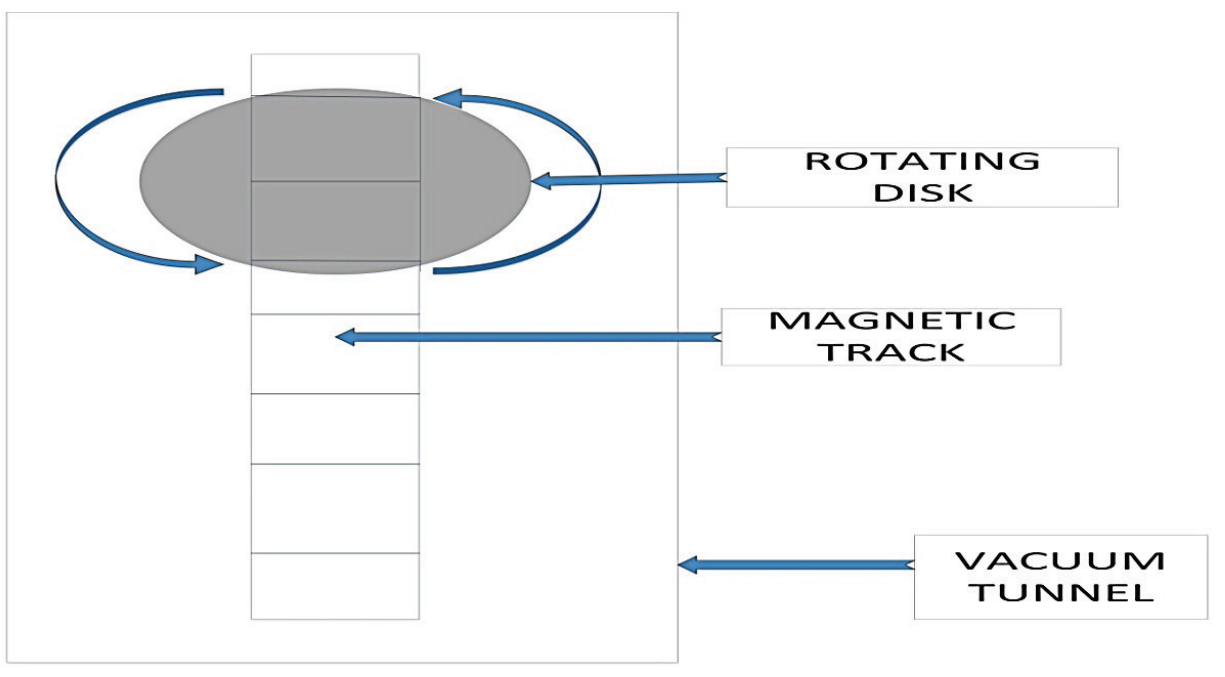

Fig. 6. Changing direction of vehicle

\section{ANALYSIS}

Analysis of detailed description

$T_{t}$ - Total temperature of compressed gas inside compressed air chamber;

$T_{e}$ - Temperature of gas on its way out from nozzle;

$A^{*}$ - Area of cross-section of choked flow region;

$A_{e}$ - Area of cross-section of exit;

$p_{t}$ - Total pressure of compressed gas inside compressed air chamber;

$p_{e}$ - Pressure of gas on its way out from nozzle;

$p_{o}$ - Free stream pressure;

$M_{e}$ - Exit Mach number;

$V_{e_{*}}-$ Exit velocity;

$m^{*}$ - Mass flow rate;

$R$ - Gas constant;

$\gamma$-Specific heat ratio.

Mass flow rate:

$$
m^{*}=\frac{A^{*} p_{t}}{\sqrt{T_{t}}} \sqrt{\frac{\gamma}{R}}\left(\frac{\gamma+1}{2}\right)^{-\frac{\gamma+1}{2(\gamma-1)}}
$$

Area ratio:

$$
\frac{A_{e}}{A^{*}}=\left(\frac{\gamma+1}{2}\right)^{-\frac{\gamma+1}{2(\gamma-1)}} \frac{\left(1+\frac{\gamma-1}{2} M_{e}^{2}\right)^{\frac{\gamma+1}{2(\gamma-1)}}}{M_{e}}
$$


Temperature ratio:

$$
\frac{T_{e}}{T_{t}}=\left(1+\frac{\gamma-1}{2} M_{e}^{2}\right)^{-1}
$$

Pressure ratio:

$$
\frac{p_{e}}{p_{t}}=\left(1+\frac{\gamma-1}{2} M_{e}^{2}\right)^{-\frac{\gamma}{\gamma-1}}
$$

Exit velocity:

$$
V_{e}=M_{e} \sqrt{\gamma R T_{e}}
$$

Force applied on the vehicle:

$$
F=m \times V_{e}+\left(p_{e}-p_{o}\right) A_{e}
$$

Now taking values of following parameter.

- $R=287 \mathrm{JKg}^{-1} \mathrm{~K}^{-1}$ (For air)

- $M_{e}=2.5$

- $\gamma=1.4$ (For air)

- $1 \mathrm{~atm}=101325 \mathrm{~N} / \mathrm{m}^{2}$

- Now from ideal gas law $p_{t} V=m R T_{t}$

Pressure of the air inside compressed air chamber

- Taking $p_{t}=2.5 \mathrm{~atm}=2.5 \times 101325 \mathrm{~N} / \mathrm{m}^{2}=253312.5 \mathrm{~N} / \mathrm{m}^{2}$

- Taking $V=L \times B \times H$

$L=$ Length of compressed air chamber $(17 \mathrm{~m})$

$B=$ Width of compressed air chamber $(2 \mathrm{~m})$

$H=$ Height of compressed air chamber $(4 \mathrm{~m})$

So, $V=136 \mathrm{~m}^{2}$

- Now $m=$ mass of air; [1 mol $=0.02897 \mathrm{Kg}$ (For air)]

- Mole of air in chamber $=\frac{136}{22.4 \times 10^{-3}}$

$175.8892857 \mathrm{Kg}$

$22.4 \times 10^{-3}$
- Mass of air $(m)=$ no. of moles $\times 0.02897 \mathrm{Kg}=\frac{136}{22.4 \times 10^{-3}} \times 0.02897=$
$892857 \mathrm{Kg}$

Now $T_{t}=\frac{p_{t} V}{m R}$

Temperature of air inside Compressed air chamber

$$
=\frac{253312.5 \times 136}{175.8892857 \times 287}=682.45535 \mathrm{~K}
$$


- Now taking equation 3, the temperature of air at Exit from vehicle:

- $T_{e}=T_{t}\left(1+\frac{\gamma-1}{2} M_{e}^{2}\right)^{-1}=682.45535\left(1+0.2(2.5)^{2}\right)^{-1}=303.313488 \mathrm{~K}$.

- Now taking equation 5, the exit Velocity:

- $V_{e}=M_{e} \sqrt{\gamma R T_{e}}=2.5 \sqrt{1.4 \times 287 \times 303.313488}=872.7519674 \mathrm{~m} / \mathrm{sec}$

- Now taking equation 2, the radius $=2 m$ of choked flow Region

$$
\text { - } A^{*}=\pi r^{2}=4 \pi=12.56637 \mathrm{~m}^{2}
$$

- Exit area of cross-section of Nozzle:

$$
\begin{gathered}
\cdot A_{e}=A^{*}\left(\frac{\gamma+1}{2}\right)^{-\frac{\gamma+1}{2(\gamma-1)}} \frac{\left(1+\frac{\gamma-1}{2} M_{e}^{2}\right)^{\frac{\gamma+1}{2(\gamma-1)}}}{M_{e}}= \\
=12.56637\left(\frac{1.4+1}{2}\right)^{-\frac{1.4+1}{2(1.4-1)}} \frac{\left(1+\frac{1.4-1}{2}(2.5)^{2}\right)^{\frac{1.4+1}{2(1.4-1)}}}{2.5}= \\
=12.56637 \times 2.6367187=33.133985 \mathrm{~m}^{2}
\end{gathered}
$$

- Now taking equation 1, here it is Mass Flow Rate:

$$
\begin{gathered}
m^{*}=\frac{A^{*} p_{t}}{\sqrt{T_{t}}} \sqrt{\frac{\gamma}{R}\left(\frac{\gamma+1}{2}\right)^{-\frac{\gamma+1}{2(\gamma-1)}}} \\
m^{*}=\frac{12.56637 \times 2.5 \times 101325}{\sqrt{682.45535}} \sqrt{\frac{1.4}{287}}\left(\frac{1.4+1}{2}\right)^{-\frac{1.4+1}{2(1.4-1)}}=4925.02765914 \mathrm{Kg} / \mathrm{sec}
\end{gathered}
$$

Now taking equation 4 , the pressure of the air on its way out from the vehicle

$$
\begin{gathered}
p_{e}=p_{t}\left(1+\frac{\gamma-1}{2} M_{e}^{2}\right)^{-\frac{\gamma}{\gamma-1}} \\
p_{e}=2.5\left(1+\frac{1.4-1}{2}(2.5)^{2}\right)^{-\frac{1.4}{1.4-1}}=
\end{gathered}
$$




$$
=2.5 \times 0.058527663466=0.146319158665 \mathrm{~atm}
$$

- Now taking equation 6.

$$
\begin{gathered}
F=m^{*} V_{e}+\left(p_{e}-p_{o}\right) A_{e}\left[\text { Here } p_{o}=0\right. \\
=(4925.02765914 \times 872.7519614)+(0.14631915 \times 101325) \times 33.133985 \\
=4298327.549464+491237.433022 \\
=4789564.982486 \mathrm{~N}=4789.564982486 \mathrm{kN}
\end{gathered}
$$

This amount of force will act on the vehicle if we provide parameter as stated above. As per our requirement related to high or low force on vehicle we can adjust parameter accordingly.

- For levitation of the vehicle.

$$
F=\frac{A B^{2}}{2 \mu_{0}}
$$

$A$ - Total area of magnet under bogie.

$B$ - Magnetic flux density.

$\mu_{0}$ - Permeability of the vacuum.

As shown in Fig. 7, when $F>m g$ then levitation of vehicle occurs.

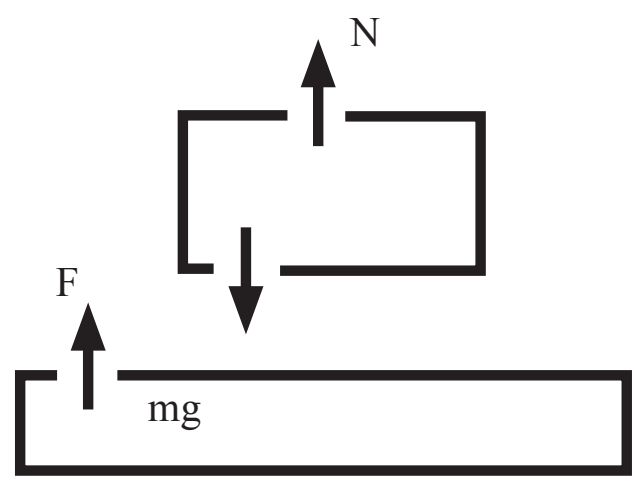

Fig. 7. Levitation

\section{CONCLUSION}

We were able to successfully demonstrate the feasibility of high-speed vacuum air vehicle. As with this technology vehicle will face negligible friction due to which force will only act to accelerate the vehicle. Dimension of the track and vehicle should be accurate in order to get better results. As per our requirement 
that is high or low force on the vehicle we can adjust parameter accordingly. With this technology we can achieve very high speed with safety ensured, and this technology can be utilized for not only train application but also for aircraft launching systems and spacecraft launching systems.

\section{References}

1. Sinha P. Design of a magnetically levitated vehicle. IEEE Trans.Magn. 1984;MAG20(5):1672-1647. doi: 10.1109/TMAG.2006.879572

2. Takahashi T, Kurita K. Computation of eddy currents induced in a conducting sheet under moving magnets. IEEE Trans. Magn. 1988;24(1):197-200. doi: 10.1109/ TMAG.2006.879572

3. Tsuchimoto M, Miya K, Yamashita A, Hashimoto M. An analysis of eddy current and Lorentz force of thin plates under moving magnets. IEEE Trans. Magn. 28(2):1434-1437. doi: 10.1109/TMAG.2006.879572

4. Nakao H, Yamashita T, Sanada Y, et al. Development of a modified superconducting magnet for Maglev vehicles. IEEE Trans. 1999;9(2):1000-1003. doi: 10.1109/ TVT.2017.2657201

5. Fujimoto H, Kamijo H, Higuchi T, et al. Preliminary study of a superconducting bulk magnet for the Maglev train. IEEE Trans. 1999;9(2):301-304. doi: 10.1109/TVT.2017.2657201

6. Sasakawa T, Tagawa $N$. Reduction of magnetic field in vehicle of superconducting maglev train. IEEE Trans. Magn. 2000;36(5):3676-3679. doi: 10.1109/TMAG.2006.879572

7. Weh H, Shalaby M. Magnetic levitation with controlled permanentic excitation. IEEE Trans. Magn. 1977;13(5):1409-1411.doi: 10.1109/TMAG.2006.879572

8. Atherton D. Maglev using permanent magnets. IEEE Trans. Magn. 1980;16(1):146-148. doi: 10.1109/TMAG.2006.879572

9. Yoshida K, Umino T. Dynamics of the propulsion and levitation systems in the controlled-PM LSM maglev vehicle. IEEE Trans. 1987;23(5):2353-2355.doi: 10.1109/ TMAG.2006.879572

10. Morishita M,Azukizawa T, Kanda S, et al. A new MAGLEV system for magnetically levitated carrier system. IEEE Trans. 1989;38(4):230-236. doi: 10.1109/TVT.2017.2657201

11. Onuki T, Toda Y. Optimal design of hybrid magnet in maglev system with both permanent and electromagnets. IEEE Trans. Magn. 1993;29(2):1783-1786. doi: 10.1109/ TMAG.2006.879572

12. Tzeng YK, Wang TC. Optimal design of the electromagnetic levitation with permanent and electro magnets. IEEE Trans. Magn.. 1994;30(6):4731-4733. doi: 10.1109/ TMAG.2006.879572

13. Wang TC, Tzeng YK. Anewelectromagnetic levitation systemfor rapid transit and high speed transportation. IEEE Trans. Magn. 1994;30(6):4734-4736. doi: 10.1109/ TMAG.2006.879572

14. Sen PC. On linear synchronous motor (LSM) for high speed propulsion. IEEE Trans. Magn. 1975;MAG-11(5):1484-1486.doi: 10.1109/TMAG.2006.879572

15. Albicini F, Andriollo M, Martinelli G, Morini A. General expressions of propulsion force in EDS-MAGLEY transport systems with superconducting coils. IEEE Trans. Appl. Supercond. 1993;3(1):425-429. doi: 10.1109/TASC.2016.2534760 
16. Sakamoto T, Shiromizu T. Propulsion control of superconducting linear synchronous motor vehicle. IEEE Trans. Appl. Supercond. 1997;33(5):3460-3462. doi: 10.1109/ TASC.2016.2534760

17. Burke P, Kunts S, Slemon G. A dual linear synchronous motor for Maglev vehicles. IEEE Trans. Magn. 1977;MAG-13(5):1415-1417.doi: 10.1109/TMAG.2006.879572

18. Koseki T, Hayafune K, Masada E. Lateral motion of a shortstator type magnetic wheel. IEEE Trans. Magn. 1987;23(5):2350-2352.doi: 10.1109/TMAG.2006.879572

19. Ohashi S, Ohsaki H, Masada E. Running characteristics of the magnetically levitated train in a curved track section. IEEE Trans. Magn. 1997;33(5):4212-4214.doi: 10.1109/ TMAG.2006.879572

20. Wang J, Wang S, Ren Z, et al. Guidance forces on high temperature superconducting Maglev test vehicle. IEEE Trans. Appl. Supercond. 2003;13(2):2154-2156.doi: 10.1109/ TMAG.2006.879572

21. Shibata M, Maki N, Saitoh T, Kobayashi T, Sawano E, Ohshima H. On-board power supply system of a magnetically levitated vehicle. IEEE Trans. 1992;28(1):474-477. doi: 10.1109/TVT.2017.2657201

22. Andriollo M, Martinelli C, Morini A, Tortella A. Optimization of the on-board linear generator in EMS-MAGLEV trains. IEEE Trans. Magn. 1997;33(5):4224-4226. doi: 10.1109/TMAG.2006.879572

23. Cassat JM. MAGLEV Projects Technology Aspects and Choices. IEEE Transactions on Applied Superconductivity. 2002;12(1):915-925. doi: 10.1109/TASC.2016.2534760

Information about the authors:

Rajat Mishra, Bachelor of Technology Student;

ORCID: 0000-0002-0332-2561

E-mail: Rjrajat678@gmail.com

Himanshu Sharma, Bachelor of Technology and Master of Technology;

ORCID: 0000-0002-6973-1069 ;

E-mail: himanshu.sharma@kiet.edu

Harshit Mishra, Bachelor of Technology;

ORCID: 0000-0002-0860-7355;

E-mail: rajatmshr179@gmail.com

\section{To cite this article:}

Mishra R, Sharma H, Mishra H. High-Speed Vacuum Air Vehicle. Transportation Systems and Technology. 2018;4(3 suppl. 1):328-339. doi: 10.17816/transsyst201843s1328-339 